\title{
Characteristics of patients admitted with Road Traffic Accidents (RTA) to General Hospital, Matara

\author{
Weerawardena WAK, ${ }^{1}$ Ubayasirinarayana SC, ${ }^{2}$ Harindra WAC, ${ }^{2}$ Buddhika $\mathrm{MSC},^{2}$
} Weththasinghe $\mathrm{I}^{2}$
}

\begin{abstract}
Introduction: Road traffic accidents(RTA) result in significant mortality and morbidity. Identification of causes for accidents, injury pattern, type of injuries help to launch preventive strategies.

MethodsWe analyzed all consecutive road traffic accident victims admitted to surgery Unit A General Hospital Matara from 01 September 2019 to 29 February 2020. We analyzed age and sex of victims, pattern of injury, possible cause for accident, influence of alcohol and use of safety equipment.

Results: There were 394 patients. 323(82\%) weremales. Average age in males was 39 years(range 5-85) and in females 41 years(range 8-83). Vehicles involved were motor bicycles 238(62\%), three wheelers 63(16\%), buses 12(3\%), Bicycles 40(10\%), cars 15(4\%). Causes for accidents were own wrong driving 160(44\%), opponent vehicle wrong driving $107(30 \%)$, animals crossing road $41(11 \%)$, mechanical failure $40(11 \%)$, poor road quality $12(3 \%)$, man crossing road 3(1\%). 92(23\%) patients had consumed alcohol at the time and $40(17 \%)$ were without helmets. The area of the body affected was head in $185(47 \%)$, limb/extremity in $243(62 \%)$, chest in $74(19 \%)$ and abdomen in $68(17 \%)$.

Conclusion: Commonest vehicle involved was motor bicycle. Males were more affected. Limb injuries(62\%) were the commonest trauma. $23 \%$ accidents are associated with alcohol drinking. Proper legislations implementation is necessary to control drunken drivers and riders without safety equipments. Wrong driving technique is the main cause for accidents(74\%).
\end{abstract}

Key words:Road traffic accidents, Injury pattern, Hospital admissions, Alcohol use,

\section{Introduction}

Road traffic accidents(RTAs) result in significant mortality and morbidity.RTAs are also associated with reduced productivity, material damage, disability.1lde ntification of causes for accidents, injury pattern, type of injuries help to launch preventive strategy of road traffic accidents.About 1.3 million people die each year in traffic-related accidents worldwide.190\% of road traffic accidents fatalities occur in low income or middle income countries where two third of the world population live.2,3 Road traffic accidents is the leading cause of death in children and young adults

1. Consultant Surgeon, General Hospital Matara.

2. Senior House Officer Surgery, General Hospital Matara.

Correponding Author:

W.A.KirthiWeerawardena,

District General Hospital, Matara

Email kirthiweera@gmail.com

(iD https://orcid.org/0000-0002-4326-6883 aged between 5-29 years. Between 2013 and 2016, there was no reductions in the number of road traffic accident deaths in any low-income country. ${ }^{1}$

Human factor is the main contributing factor of road traffic accidents. Human factors include both driving behaviour (drinking and driving, speeding, traffic law violations) and impaired skills ( lack of attention, exhaustion, physical disabilities). ${ }^{4}$ Other causes for Road Traffic Accidents include poor vehicle design, high speed of vehicle, poor roads, increased number of vehicles on given areas of road, mechanical failure of vehicle, over loading, poor lights, animal crossing the road, inadequate traffic law enforcement and delayed implementation of road safety. ${ }^{5}$

Sri Lanka is an example for exponential growth of motorization since 1977. This increase of motorization in the setting of poor road infrastructure had caused large increase of road traffic accidents. Although number of road traffic accidents has decreased since 
2003, road traffic fatalities have not shown a similar reduction. ${ }^{6}$ In Sri Lanka during 2009-2015 number ofroad traffic accidents related accidents increased by $15 \%$ while deaths increased by $17 \% .3$ The number of road traffic crashes increased from 61.2 to 195.9,injuries from 35.1 to 98.6 and fatalities from 3.0 to 10.8 per year per 100,000 populations from 1938 to 2011.6 In Sri Lanka, there are approximately 2000 deaths and 20,000 injuries per year due to road traffic crashes. Police statistics (2011) indicate that the most common vehicles involved are motorcycles, cars, and three wheelers ${ }^{7}$

In Sri Lanka limitation of availability of road safety research and road traffic accidents related statistics made it difficult for policy makers to propose interventions to prevent road traffic accidents. This research was conducted to gather road traffic accidents related statistics in Matara area.

Identification of risk factors for road traffic accidents enables to plan a preventive strategy. The risk factors for the road traffic accidents are different for each region. Although some statistics are available in Sri Lanka, these need to be reinvestigated again as recent rapid upgrading of the road systems. ${ }^{5}$ Influxes of new types of vehicles often change the pattern of risk factors. Our specific objectives are to identify the characteristics of patients with road traffic accidents.

\section{Results}

There were 394 patients. 82\%(323) were males. Average age in males was 39 years(range $5-85$ ) and in females 41 years(range $8-83$. Vehicles involved were motor bicycles 238(62\%), three wheelers 63(16\%), buses $12(3 \%)$, bicycles $40(10 \%)$, cars $15(4 \%)$. There were 7 vans, 3 tractors, 2 lorries, 2 ambulances, 3 cabs, 2 containers amount to $5 \%$. Causes for accidents were own wrong driving 160(44\%), opponent vehicle wrong driving $107(30 \%)$, animals crossing road $41(11 \%)$, mechanical failure $40(11 \%)$, poor roads $12(3 \%)$, man crossing road $3(1 \%)$. There were $20(5 \%)$ cases with high speed driving which was included in own wrong driving section. 156(40\%) of incidences taken place between $6 \mathrm{pm}$ to 6am time period.

There were $264(67 \%)$ drivers, $87(22 \%)$ passengers and $43(11 \%)$ pedestrians . 92(23\%) patients had consumed alcohol and $40(17 \%)$ motor bicyclists were without helmets. We performed 50 CT scans of brains. There were 2 Subdural haematoma(SDH), 3 Subarachnoid haemorrhage(SAH), 3 Extradural haemotoma(EDH), 4 Intracranial haemorrhage(ICH ) and 76 bone fractures. Body area affected were head 185(47\%), limb/extremity 243(62\%), chest 74 (19\%), abdomen 68(17\%).

\section{Discussion.}

Males are affected more than females(82 vs 18 per cent in our study). Motor bicycle was the main vehicle involved, Three wheelers become the second affected. These values are comparable to similar studied done at Anuradhapura and Polonnaruwa areas. 8,9

Owner driving technique (44\%) was the main cause for the accidents. This category was included high speed, wrong side driving, wrong technique of overtaking, taking acute angle at road bends, inability to react quickly to apply break. There were $5 \%$ of cases with high speed in the study group. Speed contributes up to one-third of RTIs in some studies .10 Remedial measures include road designing, enforcing speed limits, including strategic installation of cameras, traffic calming measures, and regular awareness programs. In Africa speed control bumps reduced the number of accidents by one-third, fatalities by half, and serious injuries by three-fourth.10

Wrong driving technique of opponent vehicle was the second commonest cause of accident(30\%). Combined rate of wrong driving technique(74\%) (both own and opponent) vehicle was clearly the main reason for the accidents. Wrong driving technique was the main cause for the accidents, 55\% at Polonnaruwa and $47 \%$ at Anuradhapura areas in 2 different researches done in 2017 and 2013 respectively. 8,9 It is necessary to arrange series of driving discipline teaching time to time for drivers aiming to reduce wrong driving techniques. This can be arranged when driving licenses are renewed by trained staff.

Regular driving training programs are necessary with the availability and use of new technology such as mobile phone use during driving. Slower reaction times, not keeping lane driving, deranged split decision, reduce driving performance can be observed with the use of mobile phones while driving. There is a risk of four times more likely for crashes even with use of hands-free mobile phone during driving. 10

In our study $23 \%$ of the victims were under the influence of alcohol at the time of accident.. There were $18.6 \%$ of victims with alcohol consumption in a studyconducted in Polonnaruwa idstrict in 2017.8 Alcohol consumption was $32 \%$ in RTA in Anuradhapura area in 2013 and it was 25\% in Batticoloa in 2011.5,9 
Blood alcohol level as low as $0.04 \mathrm{~g} / \mathrm{dL}$ increases the risk of road crashes significantly by impairing decision making in foreseeing the danger. Blood alcohol 0.05 $\mathrm{g} / \mathrm{dL}$ results in 1.83 times higher risk. It also causes difficulty in diagnosis, management, recovery, and prognosis from Road Traffic Accidents. 10,11,12

In India, random breath testing at police checkpoints and both breath and blood testing of all drivers involved in accidents are done. However, due to logistical deficiencies in many situations, the checking is less than expected. ${ }^{10}$ Young or beginner drivers under the influence of alcohol are prone to RTA. Indian researchers in a recent study, concluded that alcoholrelated RTA are foremost threat to civilization due to premature losses of lives with downstream socioeconomic effects on families and society that must be prevented by holistic approach. ${ }^{13}$ We suggest that strict law enforcement is necessary to control driving with alcohol use. This should include random checking for alcohol use and high fine for the wrong person.

In our study $17 \%$ of riders were without safety helmets while ridding motor bicycles. This value was $39 \%$ at Anuradhapura in 2013, 22\% at Polonnaruwa in 2017 and 35\% in Batticoloa in 2011 in different studies. $5,8,13$ United Nations Motorcycle Helmet Study (2016) estimated that motor bicycle riders have 26 times probability of death in road accidents than four wheelers. Correct wearing of best available helmet improves survival by $42 \%$ and reduces injuries by $69 \% .10$ Traumatic brain injury severity can be reduced with proper helmet use. Strict law enforcements are necessary to make all riders to use helmets.

Poor visibility of the vehicle and pedestrians are a recognized cause for accidents. It is known that majority of fatal road injuries occur in dark. Visual reaction times are substantially longer under adverse, low visibility conditions than under optimal conditions, leading to increased stopping distances when driving.

Visibility of drivers can be increased by fixing reflectors on vehicles, wearing yellow or white helmets, bright colored clothing at night. Daytime running lights of vehicles can increase the visibility. Increasing the visibility of the pedestrians by reflective clothing also increases road safety at low-light situations. ${ }^{10}$ In this study $40 \%$ of accidents happened between $6 a m$ to $6 \mathrm{pm}$ time period.

$11 \%$ of accidents were due to animals crossing the road in this study. The value was $18 \%$ at Polonnaruwa area in 2017. When animals reach roads, the owners of the dogs and cattle, should be fined with very strict laws. Mechanical failure of vehicles was responsible in $11 \%$ of cases. This value was $6 \%$ at Polonnaruwa in 2017 and 7\% at Anuradhapura in 2013. Failure of break system was the main mechanical failure. We suggest that strict law enforcement is necessary to check the mechanical system of each vehicle time to time and only certified vehicles should be given the permission to drive.

$62 \%$ of the patients had trauma to limbs and extremities with 46 fractures. Motor bicycle riders should be encouraged to use safety equipments to hands, head and lower leg areas as preventive strategies. This will reduce the post trauma morbidity. We performed 50 Computer Tomography brain scans (CT scans) of patients suspected of brain trauma. ${ }^{12}$ Patients with $\mathrm{EDH}, \mathrm{SDH}, \mathrm{SAH}$ and $\mathrm{ICH}$ were transferred to Teaching Hospital Karapitiya for neurosurgical intervention.

\section{Conclusion}

Significant amount of Road Traffic Accidents are potentially preventable. Regular update and reminding of driving discipline is needed as wrong driving techniques which is responsible for 74\% Road Traffic Accidents in this study in this regional area. Strict law enforcement against drivers under the influence of alcohol is essential. Significance of use of safety equipments during riding bicycles could be illustrated inthe media.

\section{References}

1. Woldu AB, Desta AA, Woldearegay TW.Magnitude and determinants of road traffic accidents in Northern Ethiopia: a cross-sectional study Occupational and environmental medicine(BMJ open). 2020;10(2) .http://dx.doi.org/10.1136/bmjopen-2019-034133

2.Gopalakrishnan S.Review-A public health perspective of road traffic accidents .J Family Med Prim Care. 2012;1(2):144-50. doi: 10.4103/22494863.104987.

3. Amarasinghe PG, Dharmaratne SD., 2019. Epidemiology of road traffic crashes reported in the Kurunegala Police Division in Sri Lanka. Sri Lanka Journal of Medicine, 2019; 28(1):10-19. DOI: http://doi. org/10.4038/sljm.v28i1.102

4. Nabi H, Consoli SM, Chastang J-F, et al Type A behavior pattern, risky driving behaviors, and serious road traffic accidents: a prospective study of the GAZEL cohort. Am J Epidemiol. 2005;161:864- 
70.doi:10.1093/aje/kwi110

5. Jeepura P. and Pirasath S, Road traffic accidents in Eastern Sri Lanka: An analysis of admissions and outcome. Sri Lanka Journalof Surgery, 2011; 29(2):7276.http://doi.org/10.4038/sljs.v29i2.3945

6.Dharmaratne SD, Jayatilleke AU, Jayatilleke AC. Road traffic crashes, injury and fatality trends in Sri Lanka: 1938-2013. Bull World Health Organ. 2015; 93(9): 640-647.

7.De Silva V, Tharindra H, Vissoci JRN, Andrade L, Mallawaarachchi BC, Østbye T, Staton CA. Road Traffic Crashes and Built Environment Analysis of Crash Hotspots based on local police data in Galle, Sri Lanka. Int J InjContrSafPromot. 2018 Sep; 25(3): 311-318. Published online 2018 Feb 7.

08. Weerawardena WAK, Thannegedara TGHLM, Priyantha HGV, Chandrasiri PACGS, Disanayaka WSI. Road Traffic Accidents at Polonnarauwa district. Analysis of patients admitted a surgical unit. Journal of Ruhunu Clinical Society. 2018;23(1):25-29.

09. Weerawardena WAK, Illanagasingha TDB , Piyadasa IJ , Rathnayaka SM , Subaweera WTDUPL, Niroshana GAL . Analysis of patients admitted with history of road traffic accidents to surgical unit B Teaching Hospital Anuradhapura, Sri Lanka. Anuradhapura Medical Journal 2013; 07(01): 2-5.

10.Pal R, Ghosh A, Kumar R, Galwankar S, Paul SK, Pal S, Sinha D, Jaiswal AK, Moscote-Salazar LR, Agrawal A. Public health crisis of road traffic accidents in India: Risk factor assessment and recommendations on prevention on the behalf of the Academy of Family Physicians of India. Journal of Family Medicine and Primary Care.2019;8(3):775783.

11. Gururaj G. Alcohol and road traffic injuries in South Asia: Challenges for prevention. J Coll Physicians Surgeons Pakistan 2004;14:713-8.

12.Gururaj G. The effect of alcohol on incidence, pattern, severity and outcome from traumatic brain injury. J Indian Med Assoc 2004;102:157-60.

13. Jaiswal AK, Krishna S, Agarwal A, Ghosh A, Pal R. Alcohol and road safety: Investigation and legal aspects. Al Ameen J Med Sci 2018;11:154-60. 